\title{
Posterior reversible encephalopathy syndrome as the first manifestation of chronic kidney disease
}

\author{
T Chang $^{1}$, R D Lanerolle ${ }^{1}$ \\ Ceylon Medical Journal 2012; 57: 40-41
}

\section{Introduction}

Posterior reversible encephalopathy syndrome (PRES), a term coined in 1996, describes a clinico-radiologic entity characterised by headache, seizures, decreased vision, impaired consciousness and white matter oedema in bilateral occipito-parietal regions [1]. Hypertensive encephalopathy, eclampsia, immunosuppressive/cytotoxic drugs, organ transplantation, renal disease, autoimmune diseases and vasculitides are reported risk factors of PRES $[1,2]$. Although potentially reversible, delay in treatment can result in permanent brain damage $[3,4]$.

\section{Case report}

A 25-year old female presented with recurrent seizures and impaired consciousness three days after developing increasing headache and vomiting followed by visual obscurations.

On admission, her Glasgow Coma Scale was 13/15. Although her pupils and fundi were normal, she could only perceive flashed light. She did not have any focal neurological signs or neck stiffness. Her blood pressure was 190/100 mmHg. Rest of the examination including general, respiratory and abdomen was normal.
Her haemoglobin was $7.9 \mathrm{~g} / \mathrm{dl}$. ESR and CRP were normal. Urinalysis showed 2+ proteins and 10 - 20 RBC/ hpf. Serum creatinine was $960 \mu \mathrm{mol} / \mathrm{l} ; \mathrm{Na}^{+} 128 \mathrm{mmol} / \mathrm{l}$ and $\mathrm{K}^{+} 4.1 \mathrm{mmol} / \mathrm{l}$. Ultrasonography showed marginally small kidneys with increased cortical echogenicity. Anti-nuclear antibodies were negative with normal complement levels. Renal biopsy showed 12/12 sclerosed glomeruli.

The MRI of the brain showed white matter oedema extending forwards from both occipital poles (Figure 1A). After six days of haemodialysis, rigorous blood pressure control and antiepileptic drugs she recovered complete vision, consciousness and had no further seizures. A repeat MRI done 4 weeks later showed complete resolution of the occipital white matter oedema (Figure 1B).

\section{Discussion}

Our patient presented with PRES as the first manifestation of chronic kidney disease. An acute elevation of blood pressure and the underlying kidney disease were the probable precipitants for her presentation. Reversibility of her neuro-radiologic syndrome was evident with resolution of symptoms and MR changes (Figure 1).
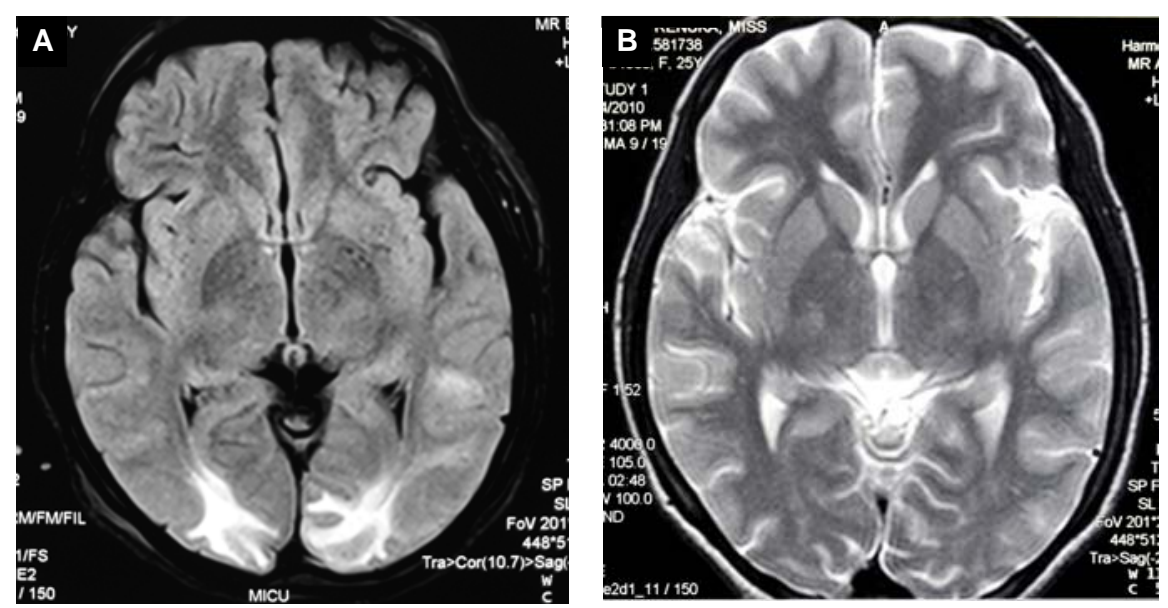

Figure 1. (A) Fluid-attenuated inversion recovery MRI of brain showing oedema confined to the white matter of both occipital poles (arrows) at the onset of illness. (B) T2-weighted MRI of the brain done 4 weeks later showing complete resolution of the white matter oedema.

\footnotetext{
${ }^{1}$ Department of Clinical Medicine, University of Colombo, Sri Lanka.
}

Correspondence: TC, e-mail: <thashichang@gmail.com>. Received 21 April and revised version accepted 14 August 2011. Competing interests: none declared. 
PRES is often misdiagnosed as bilateral occipital infarctions. However, it is important to distinguish between these conditions since it is recommended not to treat moderate hypertension in stroke while rigorous treatment of hypertension is essential in PRES. Diffusion weighted imaging (DWI) is useful in diagnosing acute infarcts, which appear hyperintense whilst regions of vasogenic oedema in PRES are visualised as hypo/iso-intense signals.

The underlying pathophysiology of PRES remains elusive. Although typically posterior and occurring in the setting of an acute rise in systemic blood pressure, PRES lesions have been reported to occur in the anterior circulation territory as well as in normotensive patients $[2,5,6]$.

\section{References}

1. Hinchey J, Chaves C, Appignani B, et al. A reversible posterior leukoencephalopathy syndrome. New England Journal of Medicine 1996; 334: 494-500.

2. Gocmen R, Ozgen B, Oguz KK. Widening the spectrum of PRES: series from a tertiary care centre. European Journal of Radiology 2007; 62: 454-9.

3. Weingarten K, Barbut D, Filippi C, Zimmerman RD. Acute hypertensive encephalopathy: findings on spin-echo and gradient-echo MR imaging. American Journal of Roentgenology 1994; 162: 665-70.

4. Schwartz RB. A reversible posterior leukoencephalopathy syndrome. New England Journal of Medicine 1996; 334: 1743-6.

5. Ay H, Buonanno FS, Schaefer PW, et al. Posterior leukoencephalopathy without severe hypertension: utility of diffusion-weighted MRI. Neurology 1998; 51: 1369-76.

6. Fugate JE, Claassen DO, Cloft HJ, et al. Posterior reversible encephalopathy syndrome: associated clinical and radiologic findings. Mayo Clinic Proceedings 2010; 85: 427-32. 